\title{
Azoospermia em garanhão - relato de caso
}

Fernando Paixão Lisboa ${ }^{[]^{*}}$, Guilherme Novello ${ }^{[a]}$, Raqueli Teresinha Françąa ${ }^{[a]}$, Rafael dos Santos Bandeira ${ }^{[b]}$, Gabriel Victoria Martins $^{[a]}$

\footnotetext{
[a] Universidade de Caxias do Sul (UCS), Caxias do Sul, RS, Brasil
}

${ }^{[b]}$ Universidade Estadual Paulista (UNESP), Botucatu, SP, Brasil

${ }^{*}$ Autor correspondente

e-mail:pxlisboa@gmail.com

\section{Resumo}

O termo azoospermia significa ausência de espermatozoides no ejaculado, podendo ser dividida em secretora ou excretora. As causas variam entre problemas no trânsito espermático, incluindo obstruções de ampola, granulomas, falhas no processo ejaculatório ou ejaculação retrógrada, e problemas na espermatogênese, como degeneração ou hipoplasia testicular. 0 objetivo deste trabalho é relatar um caso de azoospermia em um garanhão de 3 anos da raça Quarto de Milha, com histórico de infertilidade. Após inúmeras coberturas aos 2 e 3 anos de idade sem resultar em prenhez, o garanhão foi encaminhado para investigação clínica detalhada. Após sua chegada, o animal passou por exame específico do aparelho reprodutor, onde observouse testículos de tamanho reduzido e consistência flácida, os quais permaneciam constantemente encostados no corpo do indivíduo em função de um aparente encurtamento dos cordões espermáticos. Não foram observadas alterações na palpação retal e avaliação ultrassonográfica. Na primeira colheita de sêmen o garanhão apresentou boa libido. No entanto, ao final do reflexo ejaculatório, percebeu-se desconforto do animal, sendo observados poucos pulsos uretrais e um movimento de cauda atípico, sugerindo falha na ejaculação. 0 resultado do ejaculado foi um líquido de aspecto aquoso, com $13 \mathrm{ml}$ de volume e ausência de espermatozoides na avaliação microscópica. Após a colheita do sêmen, observou-se que os testículos não estavam na bolsa escrotal, permanecendo assim até 2 horas após o procedimento. Devido a esta constatação, o garanhão foi observado com frequência nos dias subsequentes, sendo confirmado que durante longos períodos do dia os testículos não se encontravam na bolsa escrotal. Visando descartar problemas ortopédicos que ocasionem dor e que possam interferir na ejaculação, foi realizada avaliação clínica criteriosa do aparelho locomotor do indivíduo, a qual não demonstrou alterações. Após a avaliação clínica, outra coleta foi realizada, sendo observado um quadro semelhante ao anterior. Na tentativa de 
identificar o tipo de azoospermia, o líquido coletado na segunda coleta foi encaminhado ao laboratório para determinação da atividade da fosfatase alcalina (FA). Essa enzima é produzida nas células do testículo e epidídimo, portanto níveis inferiores a 100 UI/l no ejaculado indicam que houve falha na ejaculação. A concentração de FA encontrada foi de 11.221 UI/l, o que confirma uma azoospermia secretora, ou seja, devido a problemas na espermatogênese. Para confirmar as condições da produção espermática do indivíduo, foi realizada citologia aspirativa com agulha fina (CAAF), onde foi observado predomínio de células de Sertoli e poucas células da linhagem espermática. Em avaliações histopatológicas de quadros severos de degeneração testicular é possível observar um elevado número de células de Sertoli em relação às demais células da linhagem espermática. Neste caso, a ausência de histórico de fertilidade associada aos achados citológicos confirma que a causa da azoospermia deste animal se deve a degeneração testicular. Na tentativa de reverter o quadro de degeneração, optou-se pela realização de um tratamento à base de nutracêutico (Botumix Garanhão Plus ${ }^{\circledR}$ ), pentoxifilina (4g/dia) e Gestran Plus ${ }^{\circledR}$ 0,05mg/dia durante 60 dias, além de duas coletas de sêmen semanais. Para o acompanhamento do tratamento, realizou-se CAAF nos momentos 30 e 60 dias de tratamento, visando avaliar o desenvolvimento das células da linhagem espermática. 0 quadro de azoospermia se manteve durante todo o tratamento, assim como o tamanho testicular e comprimento do cordão espermático. Os achados citológicos foram semelhantes à primeira colheita. De acordo com os achados da avaliação andrológica, foi diagnosticado um quadro de azoospermia secretora em função de uma degeneração testicular possivelmente causada pelo encurtamento do cordão espermático. Devido ao fundo genético da patologia, a recomendação foi castrar o garanhão.

Palavras-chave: Azoospermia. Degeneração. Hipoplasia. 